\title{
PHI TERRITORIES: NEIGHBOURHOODS OF COLLABORATION AND PARTICIPATION
}

\section{Alexandra Antonopoulou \& Eleanor Dare}

The 'Phi Books' Project is a collaborative endeavour between Alexandra Antonopoulou, a designer and children's book writer-illustrator and Eleanor Dare, a fine artist who works with code. The Phi Books use the house as a metaphor for interdisciplinary collaboration. The two researcher-artists use narrative, audience participation, code-writing, and performance to explore how borders, walls and doors facilitate collaboration.

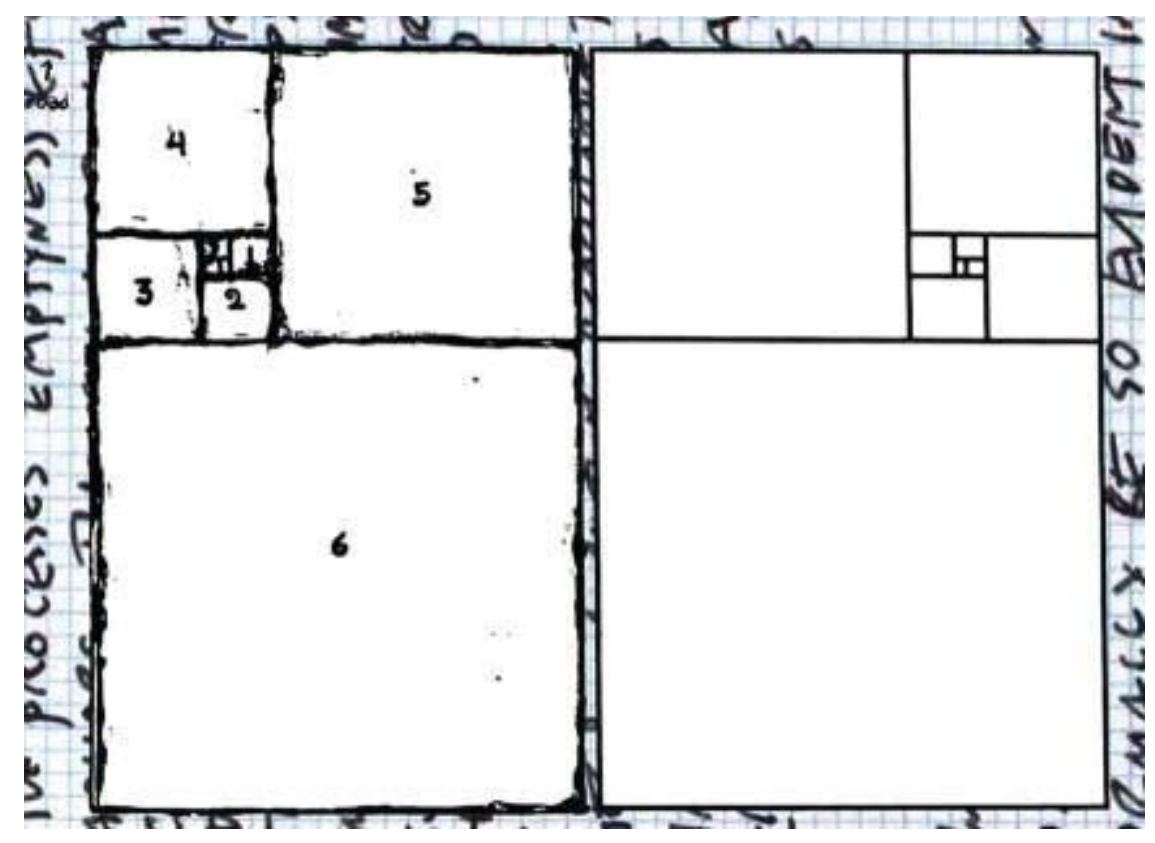

Fig 1. Poster for Phi Books, mixed media. (C) Antonopoulou \& Dare, 2009 

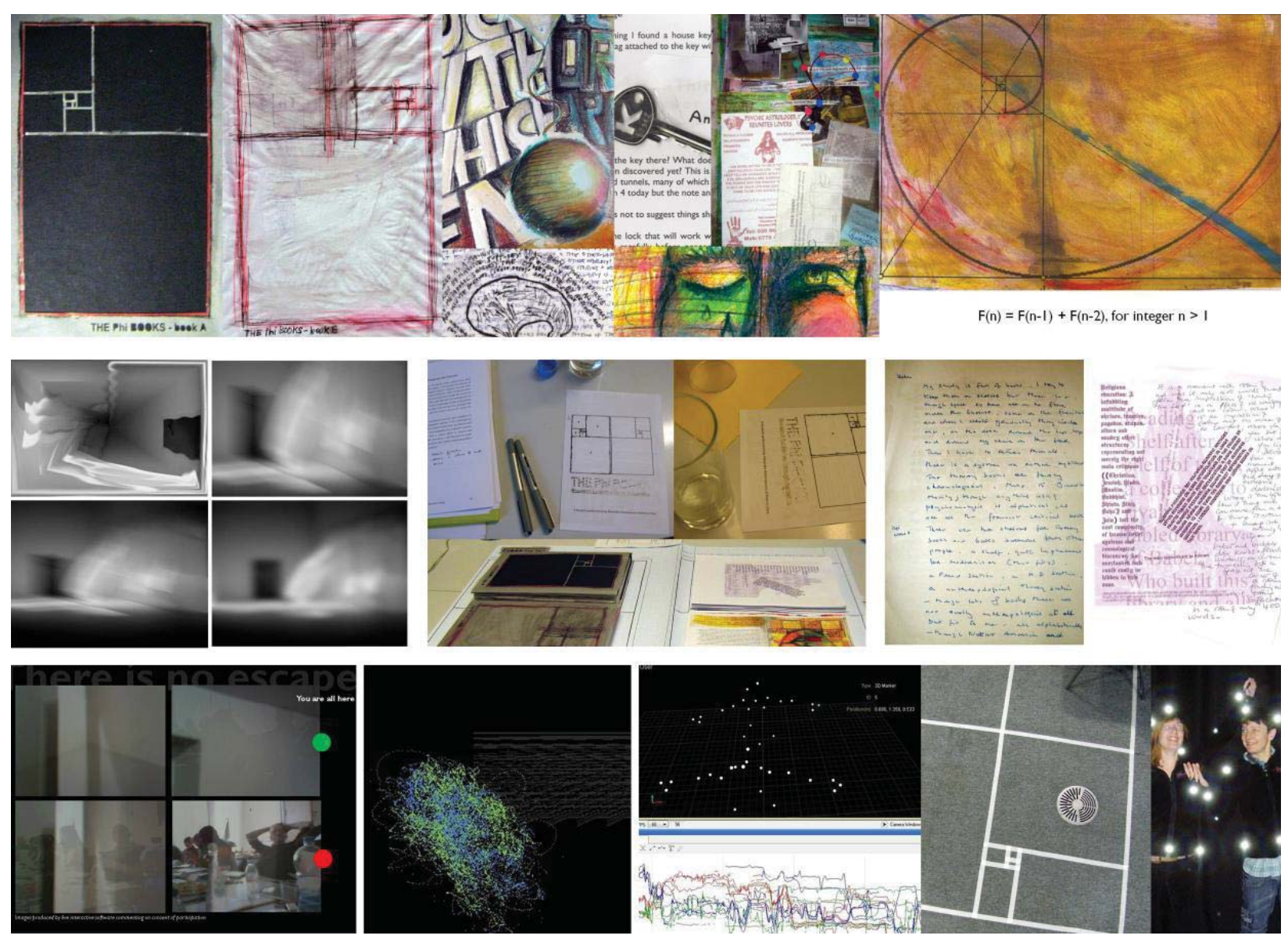

Fig 2. Top: Phi Books, Antonopoulou \& Dare, 2008. Middle: Images representing the Phi room's sounds Phi books installation- Participants' stories, Antonopoulou \& Dare, 2009. Bottom: Phi Film, interactive application playing with consent, processing application. Antonopoulou \& Dare, 2010. Participants body performance visualization with motion capture system -Phi stage from the 'Thursday Club' performanceMotion capture suit, Antonopoulou \& Dare, 2011.

E. The Phi books is a collaborative project between Alexandra Antonopoulou, a designer and children's book writer-illustrator .

A. and Eleanor Dare, a fine artist who works in code.

E. The Phi books use the house as a metaphor for interdisciplinary collaboration. This will be outlined and clarified in an article that is somewhat unorthodox in form, reflecting how our collaboration has become more and more performative. The article is therefore produced here in script-form, where we, as agent-actors ( $\mathrm{A}=$ Alexandra $\mathrm{E}=$ Eleanor) take it in turn to read out and perform our themes and findings.

A. The project evolved in different stages from the initial formulation of written algorithmic fictions to technologically mediated and embodied systems for collaboration. It uses stories, theory, drawings, maps, charts, found objects, photographs, dreams, spies, keys, overheard conversations and meta-critical observations. 
E. The Phi 'neighbourhood' or 'territories', representing our expanded practice, has extended into wider collaborative practices in which 'house stories' have been written by participants at our lectures and performances while using reiteration of mediums.

A. We were lead into more performative and interactive forms using real-time interactive programs. For example the 'Phi Film', software that played with people's consent and participation and the use of motion capture technology where we asked people to physically perform their house stories as actors and active agents exploring collaboration.

But let us tell you bits of our story.

E. Our first presentation together was in 2008 when we both presented our individual projects at a regular interdisciplinary event called the 'Thursday Club' at Goldsmiths. During the discussion we found ourselves interweaving the passage of our research projects as if they formed one bisected, inter-dependent narrative.

A. Back then I wrote: Stories were like a secret code, a silent and camouflaged set of communication rules. We needed the stories to continue to communicate with each other, we needed to have a project as a mask to fulfill our thirst for telling stories. But wait a second that means collaboration! We were both odd and we did not even want to admit that we were already collaborating, we were scared of the spies, we were scared of losing our freedom, terrified that we will end up in uncomfortable situations. [1]

E. Our research fields seemed similar and yet they are different in many important ways. The common ground we share is fiction.

A. My research focuses on the educational-social-participative-heuristic role of story-making in designing. It involves partnerships with designers and children, facilitating them to author their own material and learn through play fiction and design, while using story-making as a design concept stimulus. I also create digital and physical tools for interactive story-making and I am interested in the use of story-making as a research methodology.

E. My practice centres upon the meaningful capabilities computation has to offer the arts. Throughout the last five years I have refined my practice into one that interrogates both the collision and synergy of digital and analogue art forms. My PhD research was primarily concerned with programming situated and responsive book forms that react dynamically to contextual and subjective moments in time.

A. We used English terraced houses as a metaphor for our research. Those houses have the same architecture and seem identical, but they are different since different people inhabit them.

E. We bought two identical books which were the metaphor for our houses. We wrote stories for each room in the houses and then we swapped the books to write a response to each other's stories. This seemed to mirror an 'extreme programming' methodology in its agility and rapidity and in our attempts to 'break' each other's stories.

A. We used a mathematical algorithm to write a precise number of words for each room. The numbers of the words in each room were following the logic of the phi ratios, this was the foundational structure 
for our collaboration. Room one is 100 words. Room 2 is a room of 200 words, Room 3 is a room of 300 words. Room 4 is a room of 500 words. Room 5 is a room of 800 words. Room 6 is a room of 1300 words. [2]

E. To explain our writing algorithm: Ignoring the seed values, each remaining number is the sum of the previous two or $F(n)=F(n-1)+F(n-2)$, for integer $n>1$.

A. Room number 1 story: Room one is a tiny room just 100 words. What could it fit in a tiny space of $10 \times 10$ words? 'The little prince was pale with anger, for millions of years flowers have been growing thorns and for millions of years sheep have still been eating flowers, and is it not worth trying to understand why they do go to such lengths to grow thorns which are of no use to them?' (The Little Prince, Antoine de Saint- Exupéry). We are all sheep flowers, we eat and being eaten. [2] I used the idea of sheep flower as a metaphor for the collaboration process. We all have thorns to protect ourselves, but it is inevitable to be inspired by others and give inspiration to them as well. In our turn we are sheep taking from others even though they have thorns themselves

E. The stories are followed by note pages that reflect upon our thinking and link our stories with theoretically referenced texts.

A. By the time we reached room six, I had already instigated a full scale rebellion against the phi ratios, bursting out of their numerical constraints and inviting readers to do the same by writing their own stories. Eleanor joined in the rebellion by reverting to code, which is, of course, a type of language. At the same time she wrote in my territory, tunnelling into one of my rooms, and leaving words as provocations. She used stardust in her illustrations and these specks of shiny little dots where transferred into the whole book. That was the collaborative contamination. We used tight structures in order to define our individual territories which were eventually merged, giving birth to a wall-free collaboration.

E. In public we performed the Phi books, blurring the distinction between academic presentation and storytelling by playing the part of our fictional characters, drawing the audience into our ambiguous narratives of research and story-telling.

A. We wanted to maintain the logic of the Phi ratios in our performance as we did in our writing. We aimed to connect the linguistic to the sonic and to the spatial constraints of our collaboration.

E. We used sound to maintain the logic of the Phi ratios and to punctuate the performance. Each sound progressively expanded to reflect the increase in size of each room in the Phi house, according to the ancient Phi ratios. In the books each story's word count corresponded to the ratios of the room it was based in. We modelled the room sizes computationally to get a reverberation that was fitted to the geometry of each room.

A. In Berlin we said: This performance is based on our interpretations of the project, characterising their joint work as a paradigm for joining individual practices, leading to a result that celebrates both collaboration and individuality. We are going to take our audiences inside our Phi houses, where they can interact with the installation of our Phi neighbourhood, looking at our houses and creating their own research houses in this neighbourhood. [1] 
E. A participant wrote this: My study is full of books. I try to keep them on shelves but there isn't enough space so some are on the floor under the shelves, some on the furniture, and when I write gradually they circle me, on the desk round the lap-top and round my chair on the floor. Then I have to return them all - there is a system or rather systems.

A. We chose to put this contribution into this article, but we couldn't put them all in. How are we supposed to choose? We put them in a bucket shook them up and pulled one out. We didn't like the first one so we did it again.

E. In London at the Inter-Art Symposium (2010) we devised an interactive application to comment on consent and participation, combining the physical space of writing performance with virtual space.

A. While the application was running we said: 'Please attach a sticker to yourself. Please adhere a green sticker to signal your consent to participate, and a red sticker for dissent, meaning that you do not wish to participate in this performance. Place the sticker in a position that is clearly visible yet tasteful. Are they all in place? Then we can begin (...). Did you hear a smooth, metallic mechanism over by the door? A series of automatic locks have been activated. You are now confined in this room. Your detention gives you all ample opportunity to enjoy the fruits of participatory performance.' [3]

E. The Phi Meta Film was an interactive computer program written in Processing. It enabled us to project our own film of the Phi Books while grabbing colour values from live CCTV images of the River Thames, filtering those into the film and then gradually merging live images of the audience into that film and saving the new version. Here we have very quickly revealed our methodological foundations. Like many houses in London, the Phi houses have water flowing beneath them. The water that flows beneath our houses is an interface to the mutability our visible structures suppress. [3]

A. But is there really an 'interface' between us, a set of doors through which we will walk towards each other? Or is the concept of an interface a fallacy as Matthew Fuller has written? [4] Can there be such a thing? Right here, right now? If so, what form does it take? Is it an object or an event?

E. Our next destination was Stockholm

We stayed in a strange house in Stockholm. It had doors that lead to no where, multiple staircases. geometry was playing a large part everywhere, it all tied in somehow with the logic of the Phi Books.

A. We realized that we don't just make stories, our lives are the stories.

E. We gave a talk in the library at Stockholm University, surrounded by books, in a sort of book womb. Alexandra and I both have a past of working in libraries, we share this silent occupation with our favourite authors, Georges Perec and Jorge Luis Borges. We see libraries as neighbourhoods of storytelling, much like the terraced houses of the Phi Territories.

A. 'The only thing that remains is diving in the alleys of the books, sleepwalking guided by the books' numbers. I feel like a blind mouse guided by the book voices. I have to put them all in place otherwise I will be punished. Sometimes I put them in the wrong place on purpose to separate them from their friends and family. They are suddenly between other books with different interests; they hesitantly talk to them. When they return to their right shelves they have new stories to tell. Certain books fall all the 
time in my head, they want to fill my mind with words, they scream, read me you fool...but I am just blind mouse.' [2]

E. In 2010 we asked participants to perform their own stories. With the help of Marco Gilles and Andrea Kleinsmith and the 12 camera motion capture system at Goldsmiths we began to record the gestures and body performances of ourselves and others in recounting narratives of the rooms where we work, rest and create. The cameras translate people's movements into lines or points detaching the self. In that case the participants become agents however their movement can still reveal who they are. We also aim to record the participant's house stories with video-cameras in order to compare their graphically represented movement with their psychical self-represented performances. This will enable us to extrapolate new layers of embodied narrative and subjective articulation.

A. In our latest presentation at the Thursday club in 2011 after we performed our stories, we asked our participants to perform their own stories in real time. Even though, the Phi books became spatial (physical-virtual) neighborhoods and territories, we still want to call our project the 'Phi Books' as we believe that a book can be spatial, performable and independent, detached from its ordinary form.

E. We value, rather than problematize the difficulties of communication and mutual understanding. We looped with our participants through dizzying cycles of research and re-evaluation. The project is also a response to the inadequacy of historical models for both theorising and practicing creative research collaboration, and to an apparent lack of theoretical mobility across diverse disciplines.

A. The Phi Books entail research-by-practice in keeping with the complex and multi-faceted meanings the notion of research-by-practice evokes, and as evidenced by theorists of research and practice such as Graeme Sullivan, [5] Paul Carter, [6] Barbara Bolt. [7] and Henk Slager. [8]

Both our individual research activities and our collaborative work has contributed to our view that storytelling tools, whether analog or digital, must deploy the materiality of mediums, while also drawing upon the situatedness and subjectivity of human storytellers or story-makers.

\section{Conclusion}

E. As Stephen Wilson states, [9] we contribute to research by defining new questions, but also, at times, by 'using systematic investigative processes to develop new technological possibilities or to discover useful new knowledge or perspectives'. One of the consequences of this project has been the questions we have generated for our collective and individual research, such as:

A. How can artists/designers/researchers communicate openly with each other during collaborative processes?

E. How can people learn through performing and making stories?

A. What is a book? Is the book-form performable? 'I am the voice of the book you are writing on, your thoughts belong to me, you are part of the white pages, plain material, ink and paper. I am the carnival, I am what others see, I belong to everyone and you belong to me.' [2] 
E. Can books be written by humans via methods and procedures more familiar to computer programmers?

A. How can making in conjunction with narrative lead to design innovation? How can story-making be used as a methodology for research projects?

E. We consider the Phi Books a system and a method that was embedded with the productive possibility of its own destruction. The possibility of destroying our own methods might be framed as an aspect of the Phi Book methodology, or ecological intersubjectivity, which, to quote Graeme Sullivan 'acknowledges that the self and others are reflective and reflexive beings. This suggests that meaning is not contained within a form itself, say a person, painting or a poem, but exists within a network of social relations and discourse.' [4]

A. The Phi Books project has illuminated naturalized, internalized notions of what Bill Gaver and Phoebe Sengers describe as 'single, specific, clear interpretations of what systems are for and 'how they should be used and experienced.' [10]

E. This recognition has enabled us to step away from the 'presumption that a specific, authoritative interpretation of the systems we build is necessary, possible or desirable.' [10]

A. This is a voice from the flat next door. I am not a human; I am just a utopia machine, a placebo for my neighbours. I am helping them to hear their thoughts; they justify them through my existence. I might be an artificial pulse for the person living on the right of my flat, something completely different for someone else. I only wish there was another machine elsewhere, to hear myself ... the machine. [2] 


\section{References and Notes:}

1. Alexandra Antonopoulou, Eleanor Dare, Berlin Freie Universität,"InterArt" Berlin,16-18 November 2009.

2. Alexandra Antonopoulou and Eleanor Dare, The Phi Books, 2008, Single edition artist's books.

3. Alexandra Antonopoulou and Eleanor Dare, Presentation at London, Inter-art Symposium (GoldsmithsUniversity of London, London, March 2010).

4. Matthew Fuller, "The Impossibility of Interface," in Behind the Blip, Essays on the Culture of Software (Brooklyn, NY, USA: Autonomedia, 2003).

5. Graeme Sullivan, Art Practice as Research (Thousand Oaks, CA: Sage Publications, 2005).

6. Paul Carter, Material Thinking, The Theory and Practice of Creative Research (Carlton, Victoria: Melbourne University Press, 2004).

7.Barbara Bolt, Art Beyond Representation (London; New York: I.B.Tauris, 2003).

8. Henk Slager, Art and Reasearch, http://www.artandresearch.org.uk/v2n2/slager.html (accessed 29/06/11).

9. Stephen Wilson, Cultural Importance of Scientific Research \& Technology Development, 1996, http:// userwww.sfsu.edu/ swilson/papers/artist.researcher.html (accessed 29/07/11).

10. Bill Gavers and Phoebe Sengers, Staying open to interpretation: engaging multiple meanings in design and evaluation, 2006, http://portal.acm.org/citation.cfm?id=1142422 (accessed 28/06/11).

Leave your stories-comments in our blog http://phibooksland.blogspot.com/ 